Research Article

\title{
Blast-Casting Mechanism and Parameter Optimization of a Benched Deep-Hole in an Opencast Coal Mine
}

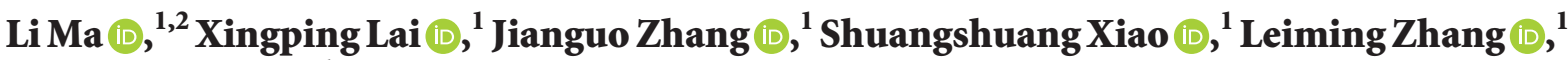 \\ and Yuhang $\mathbf{T u}$ iD \\ ${ }^{1}$ School of Energy Engineering, Xi'an University of Science and Technology, Xi'an, Shaanxi 710054, China \\ ${ }^{2}$ State Key Laboratory for Geomechanics \& Deep Underground Engineering, China University of Mining and Technology, \\ Xuzhou, Jiangsu 221116, China
}

Correspondence should be addressed to Li Ma; mali21786@hotmail.com and Yuhang Tu; 15970609409@163.com

Received 19 July 2019; Revised 28 December 2019; Accepted 10 January 2020; Published 18 February 2020

Academic Editor: Vadim V. Silberschmidt

Copyright (C) $2020 \mathrm{Li} \mathrm{Ma}$ et al. This is an open access article distributed under the Creative Commons Attribution License, which permits unrestricted use, distribution, and reproduction in any medium, provided the original work is properly cited.

During the research on bench deep-hole blast casting, the blast-casting parameters are directly related to the blast-casting results, so it could reveal the mechanism for improving the effect thereof. Based on the principle of the plane charge method, both the stress wave and detonation gas were considered to affect rock fragmentation and casting, a model of overburden fragmentation and casting process around the blasting hole was established, and bench deep-hole blast-casting behaviours were elucidated. By using the Factor Analysis Method (FAM), a correlation analysis model of factors influencing blast-casting results was built. The results proved that powder factor (or specific charge) ranked first in terms of its influence, followed by hole spacing, minimum resistance line, burden, and bench height. The formulae for calculating the limit powder factor value and the spacing of blasting holes were derived for different rock properties. The results showed that the optimum hole spacing was no more than $12.49 \mathrm{~m}$ and the powder factor was no more than $0.75 \mathrm{~kg} / \mathrm{m}^{3}$, and it proved that an effective casting percentage (ECP) of $34 \%$ could be realized.

\section{Introduction}

Blast-casting practice in opencast coal mines is characterised by large blast hole diameter and large charges. The powerful energy produced by the explosive would break the rock mass into pieces and then eject them from the working bench. Considering the goal of stripping operation in surface mining, blast-casting could not only meet the requirement of rock preparation but also reduce the material working volume for excavating and transportation. Specifically speaking, once the blast-casting technique is applied in opencast coal mines for overburden removal, $30-65 \%$ of the materials can be directly thrown into the mined-out area without any need for further handling (Figure 1); thus, it will reduce the stripping cost by more than $30 \%[1,2]$. As a matter of fact, blast-casting is the most economically effective method in opencast mining.

A greater effective casting percentage (ECP) and a better muckpile formation are the main technical targets of adopting the blast-casting method for overburden stripping in opencast mines. They are affected by several factors such as the explosive characteristics, blasting characteristics of rock mass, blasting parameters, and process. From the perspective of blasting mechanism, the fragmentation and casting process of rock mass is mainly induced by the stress wave and detonation gas. Kutter et al. studied the effect of expansive pressure of detonation gas on fragmentation of rocks and considered that the effect of air wedge of detonation gas forms a quasistatic pressure field in the rock $[3,4]$. Yang and Wang established the damage and fracture criteria for crack propagation under the effect of detonation gas and the localization model of damages at tips of fractures [5]. By performing dynamic photoelastic experiments, Rossmanith and Fourney studied effects of explosive stress waves on crack initiation and propagation [6]. Pyrak-Nolte et al. investigated the influence of discontinuity on propagation of stress waves [7-9]. Zhu et al. found that the pre-existing cracks are, to some extent, sources for the initiation of 


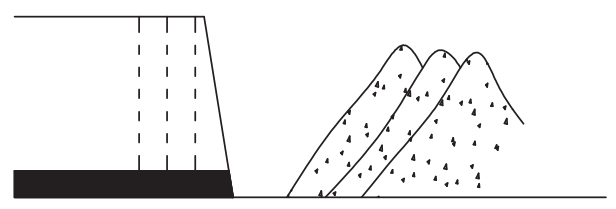

(a)

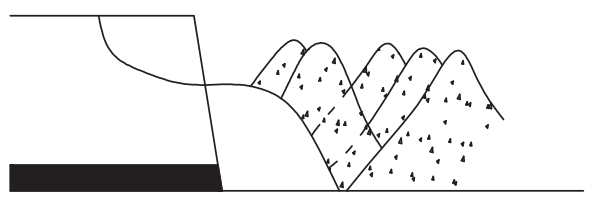

(b)

FIGURE 1: Overburden stripping by the blast-casting method in an opencast coal mine. (a) Inner-dump. (b) Blast-casting muckpile.

damage and determine the damage evolution paths as well as the final failure patterns [10]. Through experimental and theoretical analysis, Wilson explored the effects of explosive stress waves and detonation gas on bench blasting [11]. Wang and $\mathrm{Xu}$ proposed the calculation method for accumulation of damage in rocks and analysed the propagation of blasting-induced cracks by combining the dynamic effects of stress waves and the quasistatic pressure action of detonation gas in the explosion [12].

The research and application of the blast-casting technique started when Grippo analysed how to improve the ECP and the value of the main influencing factors [13]. Besides, from the perspective of blasting design, Chironis analysed the design of blasting parameters with the assistance of a computer and realised a higher blasting efficiency [14]. In addition, Singh and Singh analysed many factors affecting blast casting. These factors include, but are not limited to, design parameters (resistance, hole diameter, burden, spacing, initiation, hole pattern, dip angle of blasting holes, and hole stopping-up), material characteristics, explosive characteristics, explosive consumption, ratio of bench height to width, and charge structure, and delay time [15]. Gupta et al. also investigated such matters [16-20].

From the point of view of blast-casting application in a benched deep-hole in an opencast mine, ECP is an important indicator to measure casting effect and production cost. It depends on rock engineering geological conditions and blast hole network parameters in the blasting area. Usually, the research on improving blast-casting results is mainly focussed on parameter designs that are based on empirical formulae; however, the blasting effect is essentially a response to blasting parameters according to the prevailing blasting mechanism. In this sense, to study and reveal the mechanism of blast casting and further optimize the blast hole network parameters, it would be of great theoretical and practical significance for both improving the ECP and reducing the production cost of opencast mines.

\section{Overview of the Research Area}

Located in Zhunge'er Coalfield in the Inner Mongolia Autonomous Region, Heidaigou Surface Coal Mine (HSCM) has an annual production capacity of $33.0 \mathrm{Mt}$. The mineable and partially mineable seams in the mining area are $5 \#, 6 \#$, and $9 \#$. Of the three coal seams, 5 \# is partially mineable. As for 9 \# coal seam, its mining authority is restricted within the scope of mineral rights. Therefore, 6 \# composite seam is the main mining area with an average thickness of $28.8 \mathrm{~m}$. HSCM is divided into three mining districts: at present, the transition from the first mining district to the second has been completed. To strip the overburden above the coal seam, the blast-casting technique is applied in combination with dragline stripping. Specifically, a shovel-truck discontinuous mining system is applied in the upper loess and rock benches, and a semicontinuous mining system consisting of shovel, truck, and semifixed crushing-belt conveyor system is adopted for coal seam excavation. Rock benches at the top of the blast-casting area are divided horizontally. The coal seam in the second mining districts inclines from North to South with the dip angle increasing. As a result, the bench height for the blast-casting technique ranges from $35 \mathrm{~m}$ to $50 \mathrm{~m}$ with the width of the blasting area being $85 \mathrm{~m}$. In addition, the slope angle of the bench is $75^{\circ}$, the length of the working face is $1800 \mathrm{~m}$, the spacing of the blasting holes is $9-13 \mathrm{~m}$, and the burden is 7-9 m. Millisecond hole-by-hole detonation is adopted amongst holes and rows. In addition, presplitting blasting technology is applied [21]. Since the presplitting blasting is detonated before the main blasting hole, a presplitting surface at the boundary of blasting area and unexploded rock mass would be generated to reduce the blasting vibration effect on unexploded rock mass (Figure 2(a)). Once detonation takes place, the detonation potential energy is transmitted to the back-row blasting holes along the oblique line, and the front-row blasting holes will break the rocks into pieces and eject them from the free surface of the slope (Figure 2(b)). Due to the clamping force from the front-row blast holes, the casting effect of those in the rear would be weakened, and they would mainly play a crushing role instead (Figure 2(c)). The ECP of the blast-casting technique in HSCM can reach about $32 \%$. That means an average of 10 million cubic metres of crushed rocks are cast into the mined-out area per year, saving 120 million yuan in production cost.

\section{Overburden Blast-Casting Mechanism}

3.1. Plane Charge Method in Overburden Blast-Casting. By using the plane charge method, the broken rocks could be ejected perpendicular to the free surface, which could produce the best blasting effect. In bench deep-hole blasting in opencast mines, several columnar blast holes are usually laid out in a line, which is approximately equivalent to the plane charge method. Each hole on the charge distribution plane produces a spherical or cylindrical gas cavity after detonation, which expands rapidly in all directions at the same speed $[22,23]$. Since the rock mass exhibits strong resistance to the explosion effect, in the opposite direction of the blast hole free face, the expansion of the detonation gas would be aborted instantaneously, while it keeps expanding 


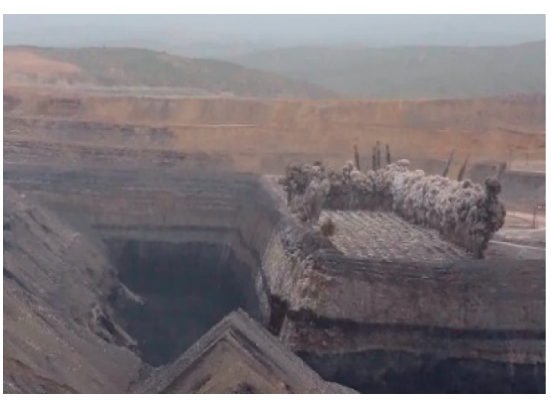

(a)

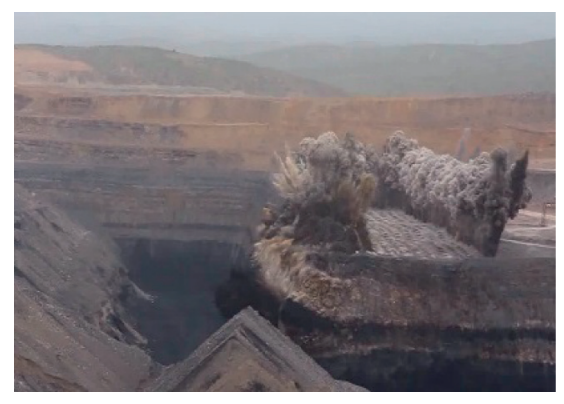

(b)

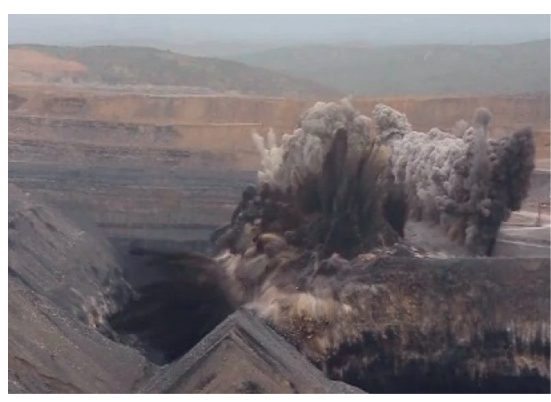

(c)

Figure 2: Blasting process (a) Detonation of the presplitting holes. (b) Detonation of the main blasting holes (c) Back-row blasting holes.

on the other side. Due to the strong compression of stress wave and detonation gas, as well as the gas wedge action of detonation gas, two adjacent holes in the same row are penetrated, and a whole gas cavity is formed that resembles a plane. On one hand, the stress inside the gas cavity is redistributed, while on the other hand, it continues to expand. Consequently, the rock medium is driven by strong compressed gas and flies out in the direction of minimum resistance, realizing plane directional casting $[24,25]$.

By researching the law of rock block casting motion under the plane charge method with larger powder factor and smaller extension size, the results show that the cavity is bulging at the final stage, and the rocks surrounding the blast hole disperse around the centre of the plane charge at a decreasing speed. When the rocks fall on the horizontal plane, an oval-like muckpile profile results; therefore, to realize the planar parallel rock casting, the profile of the broken and cast rock mass should be parallel to the original free surface profile; meanwhile, the following conditions should also be met [26]:

$$
\left\{\begin{array}{l}
\xi=\frac{L_{\mathrm{c}}}{q u W_{\mathrm{r}}} \geq 4, \\
x=\frac{B}{q u W_{\mathrm{r}}} \geq 4,
\end{array}\right.
$$

where $L_{\mathrm{c}}$ is equivalent to the length of plane charge, $m ; B$ is equivalent to the width of plane charge, $m ; q$ is the powder factor, $\mathrm{kg} / \mathrm{m}^{3} ; u$ is the specific volume of the explosive product when its adiabatic expansion reaches atmospheric pressure, $\mathrm{m}^{3} / \mathrm{kg} ; W_{\mathrm{r}}$ represents the thickness of blasting overburden, $m$; $\xi$ is equivalent to the length ratio of the plane charge; and $x$ is equivalent to the width ratio of the plane charge.

Since rocks are compact in this condition and fly at low speed, the process of rock mass casting can be decomposed into two types of motion without considering the influence of air resistance, namely uniform linear motion along the direction of casting velocity vector and equal acceleration motion under the action of gravity.

3.2. Mechanical Behaviour in the Rock Breaking and Casting Process. In the study of the rock blasting mechanism, the combined action of detonation gas and stress wave is widely used to explain rock fragmentation $[27,28]$. In the rock blast-casting practice, the purpose is always to obtain a better casting effect. In other words, under the condition of ensuring safety, cracked rock blocks could be cast as far as possible with the energy generated upon detonation.

Taking the plane charge formed by column charges as an example (Figure 3), during the development of blast-casting, the mechanical characteristics of rock mass breaking and casting around the blasting hole can be described as follows:

(1) After the explosives are detonated, a gas cavity is generated around the explosive charge, which expands violently in all directions at the same speed $[29,30]$. Due to the compressive stress influence of the strong shock wave, the compression failure and the initial fractures are formed in the rock mass around the blast hole.

The explosion generates enormous energy, which is transmitted to the rock mass at an extremely fast speed and breaks it into pieces. The energy transferred to the rock mass is closely related to the impedance matching. The pressure $P_{\mathrm{d}}$ acting on the hole wall is $[31,32]$

$$
P_{\mathrm{d}}=\frac{2 Z_{\mathrm{r}}}{Z_{\mathrm{r}}+Z_{\mathrm{e}}} P
$$

where $Z_{\mathrm{r}}$ is the impedance of rock mass, $Z_{\mathrm{r}}=\rho_{\mathrm{m}} C_{\mathrm{p}}$, $\rho_{\mathrm{m}}$ represents the rock mass density $\left(\mathrm{kg} / \mathrm{m}^{3}\right), C_{\mathrm{p}}$ is the elastic longitudinal wave velocity $(\mathrm{m} / \mathrm{s}) ; Z_{\mathrm{e}}$ represents the impedance of explosive, $Z_{\mathrm{e}}=\rho_{0} D, \rho_{0}$ is the explosive density $\left(\mathrm{kg} / \mathrm{m}^{3}\right), D$ denotes the blasting velocity of explosive $(\mathrm{m} / \mathrm{s})$, and $P$ is the explosive pressure $(\mathrm{Pa})$.

According to the gas state equation and the parameter change on the wave front before and after explosion,

$$
V=\frac{\gamma}{1+\gamma} V_{0}
$$

In combination with fundamental equation of disturbance propagation, the following can be obtained:

$$
D=V_{0} \sqrt{\frac{P-P_{0}}{V_{0}-V}}
$$

where $P_{0}$ and $V_{0}$ are the initial state parameters of the explosives when they are undisturbed; $\gamma$ is the 


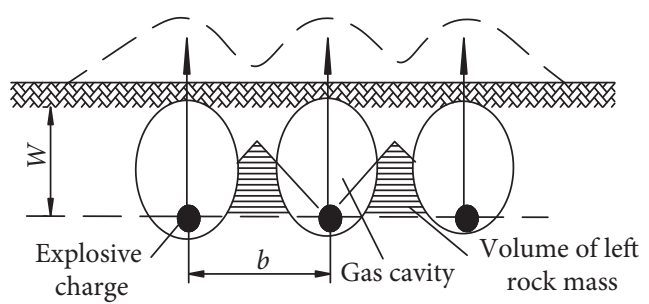

(a)

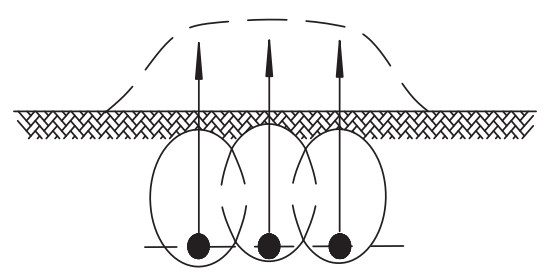

(b)

FIgURE 3: Blast-casting process of column charges forming in plane charge. (a) Widely spaced holes. (b) Closely spaced holes.

isentropic index (normally $\gamma=3$ ); and $V_{\mathrm{e}}$ is the specific heat of the detonation product.

Based on formulae (2)-(4), the pressure on the hole wall can be determined as [33]

$$
P_{\mathrm{d}}=\frac{1}{4} \rho_{0} D^{2} \frac{2 \rho_{\mathrm{m}} C_{\mathrm{p}}}{\rho_{0} D+\rho_{\mathrm{m}} C_{\mathrm{p}}} .
$$

Since the shock wave pressure acting on the rock mass around the hole wall is much greater than its compressive strength, it is certain that it would be destroyed, and as a result, the energy of the shock wave rapidly decays into stress wave outside the smashed zone. The compression stress wave continues to propagate in the rock along the radial direction, causing the rock to be subjected to radial compression and tangential tension. Although the peak pressure of stress wave is much lower than that of shock wave, it still exceeds the compressive strength of rock within a certain range, resulting in rock crushing and a crush-zone forming. As the stress wave continues to attenuate, the compressive stress would be less than the compressive strength of the rock mass, and compressive failure will no longer be generated [34]. The tensile stress acts on rock mass under the influence of the reflection and tension of the free surface. When the tensile stress borne by the rock mass exceeds its uniaxial dynamic tensile strength, it will be pulled out to form a fracture zone.

(2) Under the influence of circumferential and tangential tensile stresses, initial fractures continue to expand and promote further fragmentation of the rock mass. When the rock mass between adjacent charges is strongly compressed, the cutting effect of detonation gas penetrates adjacent blasting holes, forming a whole plane-like gas cavity along the charge distribution plane.

After detonation, the strong shock wave would first act on the surrounding rock mass and a crushed zone develops, then the detonation gas fills the blasting hole, and its initial pressure $P_{\mathrm{u}}$ could be obtained by [35]

$$
P_{\mathrm{u}}=\frac{\rho_{0} D^{2}}{2(\gamma+1)} \cdot \kappa^{-2 \lambda}
$$

where $\kappa$ is the radial decoupling coefficient.
Before the rock mass is ejected due to fracture penetration, there is no leakage of the detonation gas from the blasting hole. Hence, the process during which the detonation gas keeps expanding until it fills the entire crushed zone is regarded as an adiabatic expansion process. Influenced by both dynamic action of stress wave and static action of detonation gas, the fragmented rock mass bulges outward, approximating to an ideal gas, and the equation of state thereof is as follows [36]:

$$
P_{1} V_{1}^{\gamma}=\text { const. }
$$

Therefore, the critical state from the detonation gas generation to its leakage satisfies the following expression:

$$
P_{\mathrm{f}}=\left(\frac{V_{\mathrm{u}}}{V_{\mathrm{f}}}\right)^{\gamma} P_{\mathrm{u}},
$$

where $P_{\mathrm{f}}$ and $V_{\mathrm{f}}$ are, respectively, the detonation gas pressure $(\mathrm{Pa})$ and the volume of the detonation cavity $\left(\mathrm{m}^{3}\right)$ at the critical state of detonation gas leakage; $V_{\mathrm{u}}$ is the detonation gas volume $\left(\mathrm{m}^{3}\right)$ when it fills the blast holes.

When the initial pressure of the detonation gas in the blast hole is greater than the critical driving force required for fracture propagation, the detonation gas will result in rock cracking (Figure 4), namely,

$$
P_{\mathrm{u}}>\frac{K_{1 c}}{F \sqrt{\pi\left(r_{\mathrm{b}}+a_{0}\right)}},
$$

where $K_{1 \mathrm{c}}$ is the fracture toughness of rocks; $F$ is the coefficient related to the blast hole radius and fracture length; $r_{\mathrm{b}}$ is the blasting hole radius, $m$; and $a_{0}$ is the microcrack width caused by stress waves.

Based on formulae (8) and (9), the condition of fracture propagation can be determined as [37]

$$
P_{\mathrm{f}}>\frac{K_{1 \mathrm{c}}}{F \sqrt{\pi\left(r_{\mathrm{b}}+a_{0}\right)}} \cdot\left(\frac{V_{\mathrm{u}}}{V_{\mathrm{f}}}\right)^{\gamma} \text {. }
$$

(3) With the expansion of gas cavity, the pressure of detonation gas will be redistributed. When the detonation gas keeps expanding and acting on the surrounding rock mass, it causes fracture penetration, and, meanwhile, the rock mass is broken into 


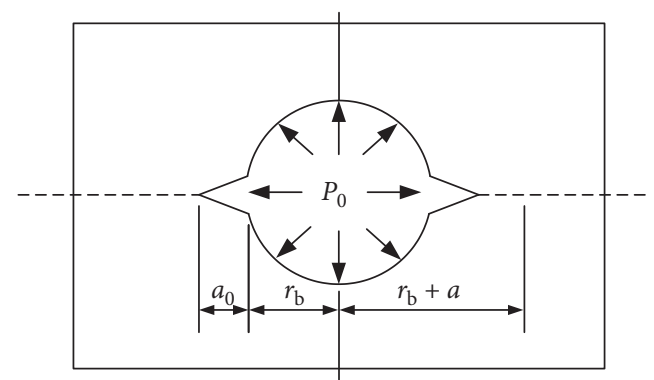

FIgURE 4: Mechanical model of rock cracking induced by detonation gas.

pieces of a certain size. Furthermore, under the powerful propelling force of the detonation gas, the shredded rock mass is cast away in the direction of minimum resistance line.

According to the mechanics of an explosion, the energy density of detonation waves emitted by various detonation products can be expressed as $[19,38]$

$$
\left\{\begin{array}{l}
E_{\mathrm{s}}=\frac{P_{\mathrm{CJ}}}{\gamma-1}, \\
E_{\mathrm{d}}=\frac{1}{2} \rho_{\mathrm{CJ}} u_{\mathrm{CJ}}^{2},
\end{array}\right.
$$

where $E_{\mathrm{s}}$ is the explosive detonation potential energy, $\mathrm{J} / \mathrm{m}^{3} ; E_{\mathrm{d}}$ is the explosive detonation kinetic energy, $\mathrm{J} / \mathrm{m}^{3} ; \rho_{\mathrm{CJ}}$ is the density of the detonation wave front, $\mathrm{kg} / \mathrm{m}^{3} ; P_{\mathrm{CJ}}$ is the pressure at the detonation wave front, $\mathrm{Pa}$; and $u_{\mathrm{CJ}}$ is the particle velocity at the detonation wave front, $\mathrm{m} / \mathrm{s}$.

$$
\left\{\begin{array}{l}
P_{\mathrm{CJ}}=\frac{1}{4} \rho_{0} D^{2}, \\
\rho_{\mathrm{CJ}}=\frac{4}{3} \rho_{0}, \\
u_{\mathrm{CJ}}=\frac{1}{4} D .
\end{array}\right.
$$

By substituting formula (12) into formula (11), the following expression could be obtained:

$$
\left\{\begin{array}{l}
E_{\mathrm{s}}=\frac{1}{8} \rho_{0} D^{2}, \\
E_{\mathrm{d}}=\frac{1}{24} \rho_{0} D^{2} .
\end{array}\right.
$$

From formula (13), the explosive detonation kinetic energy accounts for only one quarter of the total and provides rock breaking energy, while the explosives detonation potential energy accounts for about three quarters of the total energy, providing the initial velocity of rock casting. So, according to the conservation of kinetic energy, the following formula can be obtained:

$$
v=D \sqrt{\frac{\rho_{0}}{4 \rho_{\mathrm{m}}}},
$$

where $v$ is the initial casting velocity of rock fragmentation, $\mathrm{m} / \mathrm{s}$.

(4) The rock fragmentation is rapidly cast away, but such motion would be affected by gravity and air resistance until its cessation.

The motion state of the cast rock fragmentation in air meets the characteristics of external ballistic theory (Figure 5). Without considering the influence of air resistance, the cast rock fragments follow the basic motion principle of the centre-of-mass frame and runs in accordance with a ballistic trajectory [39].

$$
v=\sqrt{\frac{g S}{2\left(H^{\prime} / S+\cot \beta\right) \sin ^{2} \beta}},
$$

where $S$ is the horizontal distance between the rising and falling of cast rock fragmentation centre, $m ; \beta$ is the dip angle of the blast hole, ${ }^{\circ}$; and $H^{\prime}$ is the height difference between the rising and falling of cast rock fragmentation centre, $m$.

According to the principle of blast casting and the definition of ECP, the latter could be regarded as the effective accumulation ratio of several cast rock infinitesimals in the goaf. The casting distance is a direct factor used to characterize the ECP.

$$
S=D \sin \beta \sqrt{\frac{\rho_{0}\left(H^{\prime}+S \cot \beta\right)}{6 \rho_{\mathrm{m}} g}} .
$$

\section{Analysis of Key Influencing Factors and Optimisation of Design Parameters}

\subsection{Key Influencing Factors Analysis Model Based on FAM}

4.1.1. Basic Principles of FAM. The major factors affecting the blast-casting results include: bench height, burden, dip angle of blast holes, powder factor, delay time interval, presplitting blasting effect, blasting patterns, and so on. There is a certain correlation among these factors. As a result, when it comes to later analysis, such factors would be considered repetitively, and as a result, the theoretical analysis deviates from the practical situation. With FAM, the influence of different factors on blast-casting results could be studied by extracting relevant information among factors and by reducing the number of variables.

Suppose $X=\left(x_{1}, x_{2}, \ldots, x_{p}\right)^{\prime}$ is an observable random variable, where $X$ has been standardized, that is, the mean value of each element is zero and the variance is 1 . The original variables can be expressed using the linear relationship of $k(k<p)$ to factors such as $f_{1}, f_{2}, \ldots, f_{k}$, namely [40],

$$
x_{i}=a_{i 1} f_{1}+a_{i 2} f_{2}+\cdots+a_{i k} f_{k}+\varepsilon_{i} .
$$

The matrix is expressed as 


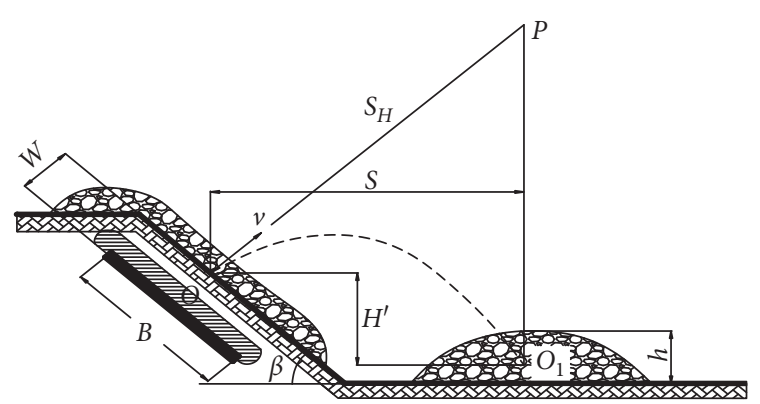

Figure 5: Blast-casting model.

$$
X=A F+\varepsilon,
$$

where $F=\left(f_{1}, f_{2}, \ldots, f_{k}\right)^{\prime}$ is a common factor, $\varepsilon=\left(\varepsilon_{1}, \varepsilon_{2}, \ldots, \varepsilon_{p}\right)$ is a special factor, $A$ is a factor load matrix, and $a_{i j}(i=$ $1,2, \ldots, p ; j=1,2, \ldots, k)$ is a factor load, namely, the correlation degree of the $j^{\text {th }}$ factor to the $i^{\text {th }}$ original variable. At the same time, the factor analysis model is assumed as follows: (1) $E\left(f_{j}\right)=0, D\left(f_{j}\right)=1$; (2) $E\left(\varepsilon_{i}\right)=0, D\left(\varepsilon_{i}\right)=\delta_{i}$; and (3) $f_{j}$ and $\varepsilon_{i}$ are mutually independent.

The variance contribution of the common factor $f_{j}$ is expressed as $S_{j}^{2}=\sum_{i=1}^{p} a_{i j}^{2}$. The following factor load matrix can be obtained when the factor analysis model is calculated by principal component analysis:

$$
A=\left[\begin{array}{cccc}
a_{11} & a_{12} & \cdots & a_{1 k} \\
a_{21} & a_{22} & \cdots & a_{2 k} \\
\vdots & \vdots & & \vdots \\
a_{p 1} & a_{p 2} & \cdots & a_{p k}
\end{array}\right]=\left[\begin{array}{cccc}
u_{11} \sqrt{\lambda_{1}} & u_{21} \sqrt{\lambda_{2}} & \cdots & u_{k 1} \sqrt{\lambda_{k}} \\
u_{12} \sqrt{\lambda_{1}} & u_{22} \sqrt{\lambda_{2}} & \cdots & u_{k 2} \sqrt{\lambda_{k}} \\
\vdots & \vdots & & \vdots \\
u_{1 p} \sqrt{\lambda_{1}} & u_{2 p} \sqrt{\lambda_{2}} & \cdots & u_{k p} \sqrt{\lambda_{k}}
\end{array}\right],
$$

where $\lambda_{1} \geq \lambda_{2} \geq \ldots \lambda_{k} \geq 0$ stands for the first $k$ eigenvalues of $X$ 's correlation coefficient matrix; $u_{j}=\left(u_{j 1}, u_{j 2}, \ldots, u_{j \mathrm{p}}\right)^{\prime}$, $(j=1,2, \ldots, k)$ denotes the eigenvector corresponding to the eigenvalue. In addition, $u_{j 1}^{2}+u_{j 2}^{2}+\cdots+u_{j p}^{2}=1$; hence, the variance contribution rate of the $j^{\text {th }}$ factor is

$$
S_{j}^{2}=\sum_{i=1}^{p}\left(u_{j i} \sqrt{\lambda_{j}}\right)^{2}=\lambda_{j} .
$$

If the absolute value of $a_{i j}$, the factor load of the $i^{\text {th }}$ row, is large in multiple columns, it shows that there is an important relationship between multiple factors and the original variable $X_{i}$, and then the information of the original variable $X_{i}$ can be expressed by multiple factors together; however, if the absolute value of $a_{i j}$, the factor load of the $j^{\text {th }}$ column, is large in multiple rows, it demonstrates that multiple variables $X_{i}$ can be explained by factor $f_{j}$, and $f_{j}$ can only represent a small part of the information about variable $X_{i}$, hence, it is atypical in explaining the original variable $X_{i}$. When this happens, the actual meaning of factor $f_{j}$ is ambiguous, and it becomes necessary to right-multiply an orthogonal matrix $T$ by factor load $A$ using the factor rotation method; thus, a new matrix will be obtained. The matrix model of the original variable is

$$
X=A F+\varepsilon=A T T^{\prime} F+\varepsilon=(A T)\left(T^{\prime} F\right)+\varepsilon .
$$

The common factor $\widetilde{F}=T^{\prime} F$ can provide a better explanation for the rotated factor load matrix, namely, $\widetilde{A}=A T$. After the factor is determined, the factor component matrix is used as the factor value coefficient between the factor and the variable, and the factor score is calculated as follows:

$$
F_{j}=\omega_{j 1} x_{1}+\omega_{j 2} x_{2}+\cdots+\omega_{j p} x_{p}
$$

where $F_{j}$ is the score of the $j$ th factor; $\omega_{j 1}, \omega_{j 2}, \ldots, \omega_{j \mathrm{p}}$ are, respectively, the factor value coefficient of the $j$ th factor at the original variable from $1^{\text {st }}, 2^{\text {nd }}$, to $p^{\text {th }} ; x_{1}, x_{2}, \ldots, x_{p}$ are, respectively, the value of the original variables from $1^{\text {st }}, 2^{\text {nd }}$, to $p^{\text {th }}$ on the sample.

4.1.2. Study of the Degree of Correlation of Factors Influencing Blast-Casting Results. Since 2007, blast-casting has been applied in HSCM. To ensure its successful application, several factors were taken into account, such as production capacity, coal seam thickness, and coal seam layered mining conditions. Based on such considerations, the width of the mining zone was determined as $80 \mathrm{~m}$, and the bench slope angle was determined as $65^{\circ}$ on the basis of prior stability requirements and optimum casting angle. The effect of blast casting was closely related to powder factor, meaning the longest casting distance, the loose coefficient, and the ECP were all correlated with powder factor, in other words, information about index factors was repeated. Nevertheless, if the blasting effect was ignored, such information would be lost; therefore, both blast-casting results and parameters were taken as variables for factor analysis. To be specific, ten key influencing factors were identified to determine their correlation to blasting effect, such as powder factor, burden, bench height, hole spacing, minimum resistance line, effective casting volume, farthest casting distance, loose volume, solid volume, and ECP.

Some 84 typical sections were selected within 14 blastcasting operations (Figure 6) and the ten key factors mentioned above were measured at each section. Some of the sectional parameter statistics are shown in Table 1, where $q\left(\mathrm{~kg} \cdot \mathrm{m}^{-3}\right)$ is powder factor, $H(\mathrm{~m})$ is bench height, $b(\mathrm{~m})$ is the burden, $a(\mathrm{~m})$ is the hole spacing, $W(\mathrm{~m})$ is minimum resistance line, $V\left(\mathrm{~m}^{3}\right)$ is the effective casting volume, $L(\mathrm{~m})$ represents the greatest casting distance, $V_{\mathrm{s}}\left(\mathrm{m}^{3}\right)$ is the loose volume, $V_{\mathrm{q}}\left(\mathrm{m}^{3}\right)$ is the solid volume, $k_{\mathrm{s}}$ is the looseness coefficient $\left(k_{\mathrm{s}}=V_{\mathrm{s}} / V_{\mathrm{q}}\right)$, and $\eta$ is the ECP.

Firstly, according to the measured data in Table 1, the correlation coefficient matrix among the original variables was obtained (Table 2). Most of the correlation coefficients among the variables were large, and so the common factors could be extracted.

KMO and Bartlett sphericity tests were conducted on statistical data, and the results showed that the value of KMO statistics was 0.627 , which indicated that the variables were generally correlated, and factor analysis may be carried out on the original variables. Meanwhile, the Sigma value of the Bartlett sphericity test was 0.000 , which met the significance 


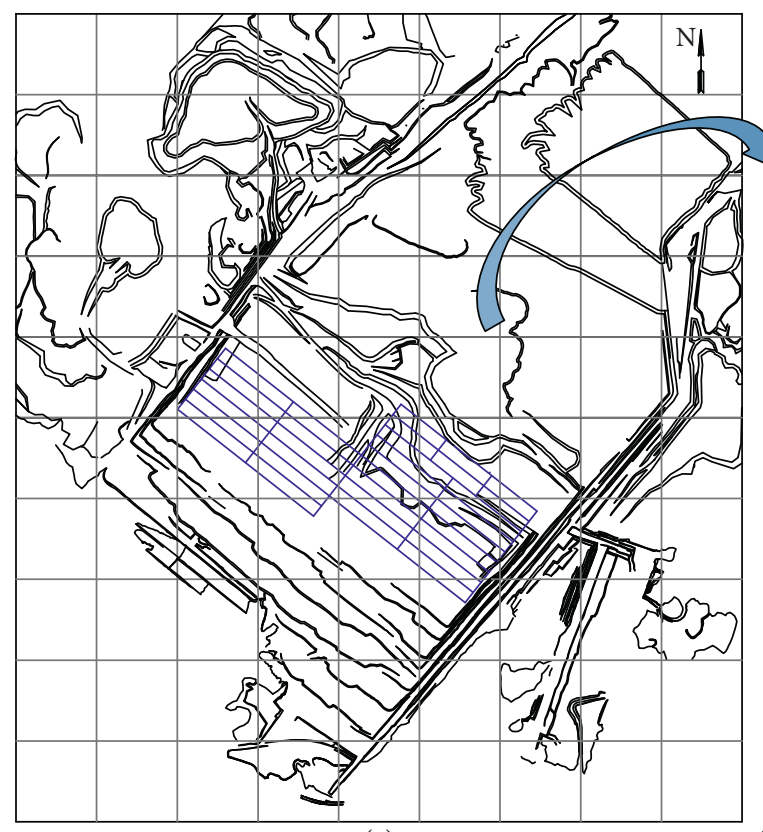

(a)

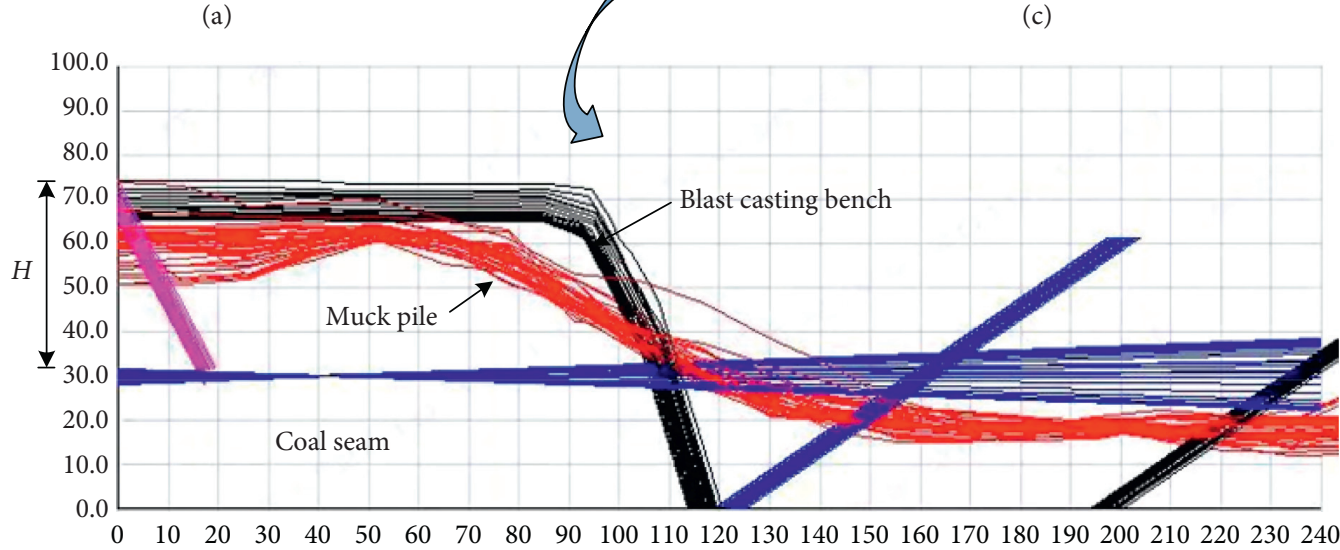

(d)

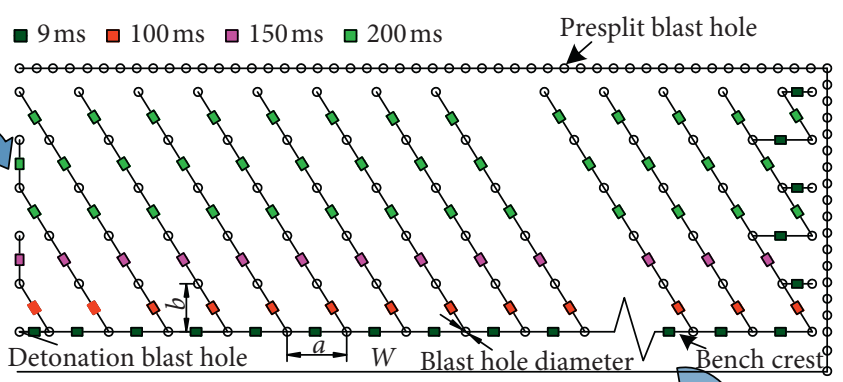

(b)

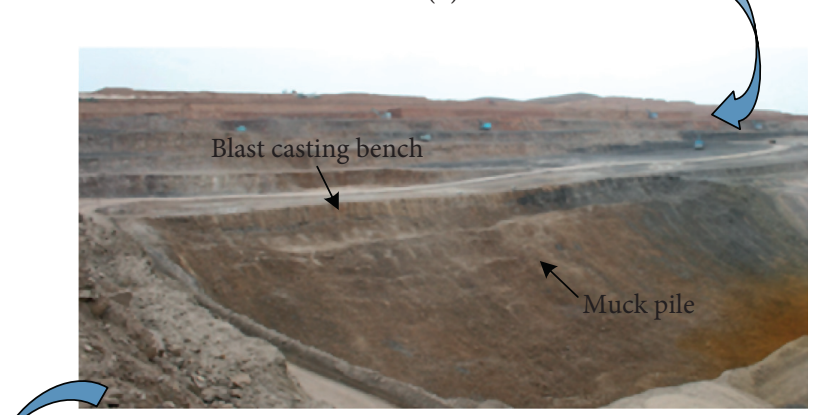

(c)

Figure 6: Schematic diagram for formation of the muckpile in blast-casting. (a) Schematic diagram of blasting zones in blast casting. (b) Schematic diagram of blast holes distribution. (c) Muck pile of blast casting in one blasting zone. (d) Vectogram of muck pile morphology obtained by scanning.

TABLE 1: Measured blast-casting parameters and results (Part).

\begin{tabular}{lccccccccccc}
\hline Profiles & $q$ & $B$ & $H$ & $a$ & $W$ & $V$ & $L$ & $V_{\mathrm{s}}$ & $V_{\mathrm{q}}$ & $k_{\mathrm{s}}$ \\
\hline P18-18 & 0.67 & 7 & 35.2 & 11 & 7 & 964.5 & 84.4 & 3474.9 & 2825.6 & 1.23 & 27.76 \\
P19-17 & 0.67 & 7 & 35.4 & 11 & 7 & 1031.1 & 85.7 & 3366.9 & 2709.5 & 1.24 & 30.63 \\
P18-17 & 0.67 & 7 & 35.6 & 11 & 7 & 1105.6 & 86.6 & 3588.6 & 2793.3 & 1.28 & 30.81 \\
P18-13 & 0.67 & 7 & 37.4 & 11 & 7 & 1105.6 & 86.6 & 3588.6 & 2793.3 & 1.28 & 30.81 \\
P19-10 & 0.67 & 7 & 39.9 & 11 & 7 & 1284.1 & 102.2 & 3890.1 & 3108 & 1.25 & 33.01 \\
P18-10 & 0.67 & 7 & 40.1 & 11 & 7 & 1286.2 & 105.9 & 3892.7 & 3207.6 & 1.21 & 33.04 \\
P18-6 & 0.67 & 7 & 43.1 & 11 & 7 & 1323.9 & 109.1 & 3979.6 & 3353.9 & 1.19 & 33.27 \\
P29-3 & 0.7 & 7 & 28.4 & 11 & 7 & 687.9 & 89.9 & 2765.2 & 2311.2 & 1.2 & 24.88 \\
P29-14 & 0.7 & 7 & 29.8 & 11 & 7 & 827 & 91.4 & 2785.5 & 2293.8 & 1.21 & 29.69 \\
P29-9 & 0.7 & 7 & 29.9 & 11 & 7 & 969.3 & 91.8 & 3040.9 & 2369.9 & 1.28 & 31.88 \\
P29-17 & 0.7 & 7 & 31.8 & 11 & 7 & 1004.5 & 94.1 & 2953.7 & 2418.8 & 1.22 & 34.01 \\
\hline
\end{tabular}

level of 0.001 , indicating that the original variables were suitable for factor analysis. Under less information loss and an $85 \%$ contribution rate of factor cumulative variance, four common factors were extracted by principal component analysis according to the correlation coefficient matrix of the original variables. 
TABLE 2: Correlation matrix of original variables.

\begin{tabular}{lccccccccccc}
\hline & $q$ & $b$ & $H$ & $a$ & $W$ & $V$ & $L$ & $V_{\mathrm{s}}$ & $V_{\mathrm{q}}$ & $\eta$ \\
\hline$Q$ & 1.00 & 0.11 & -0.20 & -0.04 & -0.09 & 0.24 & 0.14 & -0.13 & -0.28 & 0.44 \\
$B$ & 0.11 & 1.00 & -0.18 & -0.21 & 0.52 & -0.26 & -0.24 & -0.06 & -0.03 & -0.31 \\
$H$ & -0.20 & -0.18 & 1.00 & 0.02 & 0.18 & 0.61 & 0.31 & 0.82 & 0.87 & 0.14 \\
$A$ & -0.04 & -0.21 & 0.02 & 1.00 & -0.04 & 0.11 & 0.15 & -0.07 & -0.09 & 0.22 \\
$W$ & -0.09 & 0.52 & 0.18 & -0.04 & 1.00 & 0.01 & 0.00 & 0.29 & 0.31 & -0.23 \\
$V$ & 0.24 & -0.26 & 0.61 & 0.11 & 0.01 & 1.00 & 0.68 & 0.72 & 0.56 & 0.78 \\
$L$ & 0.14 & -0.24 & 0.31 & 0.15 & 0.00 & 0.68 & 1.00 & 0.26 & 0.29 & 0.74 \\
$V_{\mathrm{s}}$ & -0.13 & -0.06 & 0.82 & -0.07 & 0.29 & 0.72 & 0.26 & 1.00 & 0.87 & 0.13 \\
$V_{\mathrm{q}}$ & -0.28 & -0.03 & 0.87 & -0.09 & 0.31 & 0.56 & 0.29 & 0.87 & 1.00 & 0.03 \\
$\eta$ & 0.44 & -0.31 & 0.14 & 0.22 & -0.23 & 0.78 & 0.74 & 0.13 & 0.03 & 1.00 \\
\hline
\end{tabular}

From the component matrix and rotated component matrix (Table 3), it can be seen that component 1 had a larger load on four indices of bench height, effective casting volume, loose volume, and solid volume; component 2 had a larger load on powder factor, farthest casting distance, and ECP; component 3 had a larger load on burden and minimum resistance line. Component 4 was used to explain the hole spacing. The component score coefficient matrix is shown in Table 4.

The weights of the original variables were determined by component scores, where $F_{i j}$ is the numerical value of the $j^{\text {th }}$ $(j=1,2,3,4)$ component at the $i^{\text {th }}(i=1,2, \ldots, 10)$ variable, $S_{j}$ is the sum of the absolute values of all the component scoring coefficients about the $j^{\text {th }}$ component, and then the weight of the $i^{\text {th }}$ original variable is

$$
W_{i}=\sum_{j=1}^{4} \frac{\left|F_{i j}\right|}{S_{j}} .
$$

According to formula (23), the following results could be obtained: $W_{1}=0.644, W_{2}=0.489, W_{3}=0.270, W_{4}=0.590$, $W_{5}=0.535, W_{6}=0.285, W_{7}=0.291, W_{8}=0.268, W_{9}=$ 0.292 , and $W_{10}=0.336$. In factor analysis, not only were the influencing factors considered, but also the effects directly related to the factors were considered as the original variables; therefore, in the final analysis, the effect variables were eliminated, the components' original variables were normalized, and the weights were determined to be $0.255,0.193$, $0.107,0.233$, and 0.212 , respectively. In conclusion, in terms of the correlation order, powder factor ranked first, followed by hole spacing, minimum resistance line, burden, and then bench height.

4.2. Optimisation of Key Parameters for Bench BlastCasting. According to the ordering relation of parameters determined by FAM, powder factor and hole spacing were the most important parameters affecting the ECP; the minimum resistance line and burden were similar in a physical sense and had a linear relationship with hole spacing; the rock bench height was determined by mining parameters. It was fixed in each blasting operation and will not lead to a disparate impact on the effect of different sections in each blasting area. Therefore, powder factor and hole spacing were the key targets when optimizing the blasting parameters.
4.2.1. Optimization of the Powder Factor. The determination of the powder factor was closely related to the charge quantity and blasting capacity of the blast hole, as expressed by

$$
q=\frac{Q}{a b H}
$$

where $q$ is the UEC, $\mathrm{kg} / \mathrm{m}^{3}$; $Q$ is the charge quantity in the blast hole, kg; $a$ represents the spacing, $m$; $b$ is the burden, $m$; and $H$ is the bench height, $m$.

The amount of charge in the blast hole is limited by the charge length, which can be calculated as follows:

$$
Q \leq \pi r_{\mathrm{b}}^{2}\left(\frac{H}{\sin \beta+h-l_{d}}\right) \rho_{0},
$$

where $\beta$ is the dip angle of the blast hole, ${ }^{\circ} ; h$ is the ultradeep length of the blast hole, $m$; $l_{\mathrm{d}}$ is the length of blast hole stemming, $m$.

According to formulas (24) and (25), the limiting powder factor can be identified as follows:

$$
q \leq \frac{\pi r_{\mathrm{b}}^{2}\left(H /\left(\sin \beta+h-l_{\mathrm{d}}\right)\right) \rho_{0}}{a b H} .
$$

4.2.2. Hole Spacing Optimisation Method. The essence of rock blasting with cylindrical charges is that multiple cylindrical charges break the overburden into pieces. Therefore, the fragmentation of rock mass within the spacing of blasting holes is shared by two adjacent blasting holes. When it comes to the internal effect of single charge blasting, in addition to an enlarged cavity at the charge, a smashed zone, a broken zone (including crushed and fractured zones), and a vibration zone would also be produced from the blasting source. The shock wave attenuates rapidly in the smashed zone, and its radius is smaller; hence, the broken zone plays a major role in rock fragmentation.

At the interface of the smashed zone, the shock wave attenuates to a stress wave and the wave velocity attenuates to the elastic longitudinal wave velocity in rock mass, where the peak pressure is

$$
P_{\mathrm{r}}=\rho_{\mathrm{m}} C_{\mathrm{p}} u_{\mathrm{r}}=\frac{\rho_{\mathrm{m}} C_{\mathrm{p}}\left(C_{\mathrm{p}}-a^{\prime}\right)}{b^{\prime}},
$$


TABle 3: Component matrix and rotated component matrix.

\begin{tabular}{lcccccccc}
\hline & \multicolumn{3}{c}{ Initial factor } & \multicolumn{3}{c}{ Rotation factor } \\
& 1 & 2 & 3 & 4 & 1 & 2 & 3 \\
\hline$q$ & 0.005 & 0.530 & $\mathbf{0 . 6 3 9}$ & -0.213 & -0.360 & $\mathbf{0 . 7 0 0}$ & 0.168 \\
$b$ & -0.268 & -0.458 & $\mathbf{0 . 7 2 0}$ & 0.129 & -0.148 & -0.101 & $\mathbf{0 . 8 6 1}$ \\
$H$ & $\mathbf{0 . 8 3 8}$ & -0.356 & -0.175 & -0.041 & $\mathbf{0 . 9 2 2}$ & 0.090 & -0.046 & 0.208 \\
$a$ & 0.096 & 0.320 & -0.244 & $\mathbf{0 . 8 5 4}$ & -0.082 & 0.123 & -0.049 & $\mathbf{0 . 9 3 6}$ \\
$W$ & 0.136 & $-\mathbf{0 . 5 9 3}$ & 0.536 & 0.412 & 0.278 & -0.092 & $\mathbf{0 . 8 5 2}$ & 0.128 \\
$V$ & $\mathbf{0 . 9 2 0}$ & 0.278 & 0.151 & -0.051 & 0.623 & $\mathbf{0 . 7 4 0}$ & -0.108 \\
$L$ & $\mathbf{0 . 6 6 4}$ & 0.455 & 0.157 & 0.130 & 0.306 & $\mathbf{0 . 7 3 1}$ & -0.104 \\
$V_{\mathrm{s}}$ & $\mathbf{0 . 8 4 5}$ & -0.407 & -0.004 & -0.096 & $\mathbf{0 . 9 2 4}$ & 0.145 & 0.055 \\
$V_{\mathrm{q}}$ & $\mathbf{0 . 8 0 7}$ & -0.512 & -0.092 & -0.050 & $\mathbf{0 . 9 5 6}$ & 0.007 & 0.226 \\
$\eta$ & 0.559 & $\mathbf{0 . 7 5 4}$ & 0.216 & 0.026 & 0.067 & $\mathbf{0 . 9 2 0}$ & -0.096 \\
\hline
\end{tabular}

TABle 4: Component score coefficient matrix.

\begin{tabular}{lcccc}
\hline & Component 1 & Component 2 & Component 3 & Component 4 \\
\hline$Q$ & -0.18 & 0.392 & 0.171 & -0.295 \\
$B$ & -0.07 & 0.079 & 0.552 & -0.076 \\
$H$ & 0.289 & -0.054 & -0.057 & -0.004 \\
$A$ & -0.066 & -0.006 & 0.104 & 0.878 \\
$W$ & 0.056 & 0.019 & 0.571 & 0.228 \\
$V$ & 0.133 & 0.262 & -0.011 & -0.033 \\
$L$ & 0.027 & 0.277 & 0.027 & 0.142 \\
$V_{\mathrm{s}}$ & 0.282 & -0.006 & 0.03 & -0.097 \\
$V_{\mathrm{q}}$ & 0.304 & -0.075 & 0.02 & -0.044 \\
$\mathrm{H}$ & -0.06 & 0.376 & -0.038 & 0.051 \\
\hline
\end{tabular}

where $u_{\mathrm{r}}$ is the motion velocity of rock particles at the interface of smashed zone, $\mathrm{m} / \mathrm{s} ; a^{\prime}$ and $b^{\prime}$ are rock-related constants determined by experiment.

On the other hand, according to the attenuation relationship between the peak pressure of shock wave and distance, the peak pressure of shock wave at the interface of smashed zone can be expressed as follows [41]:

$$
P_{\mathrm{r}}=P_{\mathrm{d}}\left(\frac{r_{\mathrm{b}}}{R_{0}}\right)^{3}
$$

where $R_{0}$ is the radius of the smashed zone, $m$.

According to formulae (27) and (28), $R_{0}$ could be determined as

$$
R_{0}=r_{\mathrm{b}}\left[\frac{b^{\prime} P_{\mathrm{d}}}{\rho_{\mathrm{m}} C_{\mathrm{p}}\left(C_{\mathrm{p}}-a^{\prime}\right)}\right]^{(1 / 3)} .
$$

While outside the smashed zone lies the crushed zone generated by the compressive stress wave, its radius is [42]

$$
R_{\mathrm{c}}=R_{0}\left(\frac{P_{\mathrm{r}}}{\sigma_{c}}\right)^{\alpha}=R_{0}\left[\frac{\rho_{\mathrm{m}} C_{\mathrm{p}}\left(C_{\mathrm{p}}-a^{\prime}\right)}{b^{\prime} \sigma_{\mathrm{c}}}\right](1 / \alpha) .
$$

where $\sigma_{\mathrm{c}}$ is the rock compressive strength, $\mathrm{Pa}$.

The radial crack in rock caused by tangential tensile stress is the main cause of rock blasting damage; the radius of the fracture zone is

$$
R_{\mathrm{T}}=R_{0}\left[\frac{\lambda P_{\mathrm{r}}}{\sigma_{\mathrm{T}}}\right]^{(1 / \alpha)}=R_{0}\left[\frac{\lambda \rho_{\mathrm{m}} C_{\mathrm{p}}\left(C_{\mathrm{p}}-a^{\prime}\right)}{b^{\prime} \sigma_{\mathrm{T}}}\right]^{(1 / \alpha)} .
$$

where $\lambda$ is a coefficient related to Poisson's ratio of the rock and the propagation distance of the stress wave, and $\lambda=\mu /(1-\mu) ; \sigma_{\mathrm{T}}$ is the tensile strength of the rock, Pa; $\alpha$ is the attenuation coefficient, and $\alpha=2-\mu /(1-\mu)$, therefore, from the perspective of the internal role of the explosive, to ensure a better blasting and fragmentation effect, the spacing of blast holes should meet the requirements of the expression $a \leq 2 R_{\mathrm{T}}$ (Figure 7), i.e.

$$
\left\{\begin{array}{l}
a \leq 2 R_{\mathrm{T}}, \\
R_{\mathrm{T}}=R_{0}\left[\frac{\lambda \rho_{\mathrm{m}} C_{\mathrm{p}}\left(C_{\mathrm{p}}-a^{\prime}\right)}{b^{\prime} \sigma_{\mathrm{T}}}\right]^{(1 / \alpha)}, \\
R_{0}=r_{\mathrm{b}}\left[\frac{b^{\prime} P_{\mathrm{d}}}{\rho_{\mathrm{m}} C_{\mathrm{p}}\left(C_{\mathrm{p}}-a^{\prime}\right)}\right]^{(1 / 3)} .
\end{array}\right.
$$

4.2.3. Optimization and Application of Blast-Casting Parameters. According to the geological conditions, the rocks in the bench were mainly medium sandstone, and the inclined blasting holes were used in the blast-casting. The relevant parameters are listed in Table 5.

According to formulae (29) $-(31), R_{0}=0.12 \mathrm{~m}, R_{\mathrm{c}}=3.52 \mathrm{~m}$, and $R_{\mathrm{T}}=6.43 \mathrm{~m}$, respectively. According to formula (32), $a \leq 12.49 \mathrm{~m}$, meaning the optimum hole spacing was no more than $12.49 \mathrm{~m}$. On the other hand, formula (29) demonstrates that the powder factor was closely related to the hole spacing. Specifically, the larger the hole spacing, the smaller the powder factor. When the optimal hole spacing was identified as $12 \mathrm{~m}$, the powder factor $q \leq 0.75 \mathrm{~kg} / \mathrm{m}^{3}$ under conditions of continuous charge. To rank the key factors in terms of their degree of influence, burden and minimum resistance line followed hole spacing and powder factor; hence, the original burden and resistance line parameters were retained. After optimization of blast-casting results, the ECP could be significantly increased to $34 \%$. 


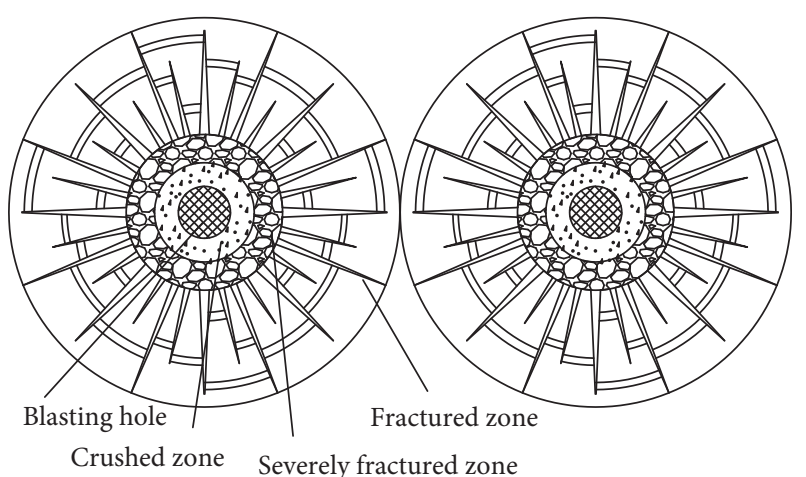

FIGURE 7: Schematic diagram of the distance between two adjacent blast holes.

TABLE 5: Relevant calculation parameters.

\begin{tabular}{|c|c|c|c|c|}
\hline & Item & Symbol & Value & Unit \\
\hline \multirow{7}{*}{$\begin{array}{l}\text { Rock } \\
\text { parameters }\end{array}$} & Rock density & $\rho_{\mathrm{m}}$ & $2.24 \times 10^{3}$ & $\mathrm{~kg} / \mathrm{m}^{3}$ \\
\hline & Poisson's ratio & $\mu$ & 0.22 & - \\
\hline & $\begin{array}{c}\text { Elastic longitudinal } \\
\text { wave velocity in } \\
\text { rocks }\end{array}$ & $C_{\mathrm{p}}$ & 2406 & $\mathrm{~m} / \mathrm{s}$ \\
\hline & $\begin{array}{l}\text { Rock compressive } \\
\text { strength }\end{array}$ & $\sigma_{\mathrm{c}}$ & 17.5 & $\mathrm{MPa}$ \\
\hline & Rock tensile strength & $\sigma_{\mathrm{T}}$ & 1.75 & $\mathrm{MPa}$ \\
\hline & Rock constant & $a^{\prime}$ & 520 & - \\
\hline & Rock constant & $b^{\prime}$ & 1.78 & - \\
\hline \multirow{2}{*}{$\begin{array}{l}\text { Explosive } \\
\text { parameters }\end{array}$} & Density of explosives & $\rho_{0}$ & 850 & $\mathrm{~kg} / \mathrm{m}^{3}$ \\
\hline & $\begin{array}{l}\text { Detonation velocity } \\
\text { of explosives }\end{array}$ & $D$ & 3000 & $\mathrm{~m} / \mathrm{s}$ \\
\hline \multirow{5}{*}{$\begin{array}{l}\text { Blast hole } \\
\text { parameters }\end{array}$} & Radius of blast hole & $r_{\mathrm{b}}$ & 155 & $\mathrm{~mm}$ \\
\hline & $\begin{array}{l}\text { Dip angle of blast } \\
\text { hole }\end{array}$ & $\beta$ & 75 & 。 \\
\hline & $\begin{array}{l}\text { Ultradeep length of } \\
\text { blast hole }\end{array}$ & $h$ & 2 & $\mathrm{~m}$ \\
\hline & Stemming length & $l_{\mathrm{d}}$ & 6 & $\mathrm{~m}$ \\
\hline & Bench height & $H$ & 40 & $\mathrm{~m}$ \\
\hline
\end{tabular}

\section{Conclusion}

(1) We took into account both the internal role that stress wave and gaseous pressure play in rock fragmentation and casting and also the external role of rock mass movement. Based on such considerations and the principles of the plane charge method, a model of rock fragmentation and casting process around the blasting hole was established, and the mechanism and mechanical behaviour of bench deep-hole blast-casting practice were revealed.

(2) The effects of different blasting parameters on the blasting effect are interrelated. In this condition, an analysis model of the correlation degree of the influence factors on the blasting effect was established by using FAM. According to the relevant parameters measured in the field and by calculation, the powder factor ranked first in terms of its influence on blastcasting results, followed by hole spacing, minimum resistance line, burden, and then bench height.
Hence, optimizing the index with high correlation degree turned out to be the most important way to improve the blasting effect.

(3) The formula for calculating the limit value of the powder factor was obtained according to the charge conditions of the blasting holes and the amount of overburden. Besides, the range of the fracture zone around the blasting holes played an important role in influencing the effect of rock blasting fragmentation. Based on the distance between two adjacent blasting holes and the respective radius of the crushed zone, the crushed zone and the fracture zone that were generated by the rock blasting mechanism, the formula for calculating the hole spacing was derived with varying rock properties. After optimization, the optimum spacing was determined as not more than $12.49 \mathrm{~m}$, and the powder factor was not more than $0.75 \mathrm{~kg} / \mathrm{m}^{3}$. On top of these, through field application, it was shown that a significant ECP of $34 \%$ could be realized.

\section{Data Availability}

The data used to support the findings of this study are available from the corresponding author upon request.

\section{Conflicts of Interest}

The authors declare that there are no conflicts of interest regarding the publication of this paper.

\section{Acknowledgments}

This study was supported by the National Natural Science Foundation of China (51604264), Scientific Research Program Funded by Shaanxi Provincial Education Department (18JK0520 and 18JS067), 973 Key National Basic Research Program of China (2015CB251602), the China Postdoctoral Science Foundation (2018M643691 and 2016M601913), Shaanxi Innovation Capacity Support Program (2018TD038), and Young Faculty Innovation Program of Engineering School (XUST, 2017-NY-001). Support from these agencies is gratefully acknowledged.

\section{References}

[1] K. M. Li, Y. D. Zhang, and H. X. Fu, "Analysis of casting blast parameters in surface coal mines," Journal of Mining \& Safety Engineering, vol. 23, no. 4, pp. 423-426, 2006, in Chinese.

[2] L. Ma, K. M. Li, X. H. Ding et al., "Development and application of blast casting technique in Large-Scale surface mines: a case study of Heidaigou surface coal mine in China," Shock and Vibration, vol. 2016, Article ID 8496742, 11 pages, 2016.

[3] H. K. Kutter and C. Fairhurst, "On the fracture process in blasting," International Journal of Rock Mechanics and Mining Sciences \& Geomechanics Abstracts, vol. 8, no. 3, pp. 181-202, 1971.

[4] T. N. Hagan, "Rock breakage by explosives," Acta Astronautica, vol. 6, no. 79, pp. 329-340, 1979. 
[5] X. L. Yang and M. S. Wang, "Mechanism of rock crack growth under detonation gas loading," Explosion and Shock Waves, vol. 21, no. 2, pp. 111-116, 2001.

[6] H. P. Rossmanith and W. L. Fourney, "Fracture initiation and stress wave diffraction at cracked interfaces in layered media I. brittle/brittle transition," Rock Mechanics Felsmechanik Mécanique des Roches, vol. 14, no. 4, pp. 209-233, 1982.

[7] L. J. Pyrak-Nolte, L. R. Myer, and N. G. W. Cook, "Anisotropy in seismic velocities and amplitudes from multiple parallel fractures," Journal of Geophysical Research, vol. 95, no. B7, pp. 11345-11358, 1990.

[8] X. F. Deng, S. G. Chen, J. B. Zhu, Y. X. Zhou, Z. Y. Zhao, and J. Zhao, "UDEC-AUTODYN hybrid modeling of a large-scale underground explosion test," Rock Mechanics and Rock Engineering, vol. 48, no. 2, pp. 737-747, 2015.

[9] S. G. Chen, J. G. Cai, J. Zhao, and Y. X. Zhou, "Discrete element modelling of an underground explosion in a jointed rock mass," Geotechnical and Geological Engineering, vol. 18, no. 2, pp. 59-78, 2000.

[10] J. B. Zhu, T. Zhou, Z. Y. Liao, L. Sun, X. B. Li, and R. Chen, "Replication of internal defects and investigation of mechanical and fracture behaviour of rock using 3D printing and 3D numerical methods in combination with X-ray computerized tomography," International Journal of Rock Mechanics and Mining Sciences, vol. 106, no. 6, pp. 198-212, 2018.

[11] W. H. Wilson, An Experimental and Theoretical Analysis of Stress Wave and Gas Pressure Effects in Bench Blasting, University of Maryland, College Park, MD, USA, 1987.

[12] J. L. Wang and Y. Xu, "Damage effect in rock by strain waves and crack propagation by explosion," Explosion and Shock Waves, vol. 15, no. 3, pp. 212-216, 1995.

[13] A. P. Grippo, "How to get more cast per blast," Coal Age, vol. 89, no. 12, pp. 63-69, 1984.

[14] N. P. Chironis, "Improving blasting improves efficiency," Coal, vol. 26, no. 7, pp. 36-41, 1989.

[15] D. P. Singh and M. M. Singh, "Blast casting in surface excavations- a global scenario," Mining Technology, vol. 78, no. 894, pp. 55-59, 1996.

[16] R. N. Gupta, G. R. Adhikari, and B. Singh, "Advances in overburden blast-casting," Journal of Mines, Metals \& Fuels, vol. 34, no. 11, pp. 487-492, 1986.

[17] G. K. Pradhan, O. Prakash, and N. R. Thote, "Blast free mining in indian surface coal mines-current trend," Mine Planning and Equipment Selection, Springer, Berlin, Germany, pp. 335-357, 2014.

[18] S. V. Ali, "Casting of overburden by directional blasting," Journal of Mines, Metals \& Fuels, vol. 35, no. 6, pp. 223-225, 1987.

[19] S. K. Ray, A. Zutshi, and M. Sarkar, "Cast blasting - state of the art," Fragblast, vol. 3, no. 4, pp. 291-302, 1999.

[20] P. D. Sharma, "Overburden side casting by blasting- an effective way of reducing operating cost in large opencast coal mines," Journal of Mines, Metals \& Fuels, vol. 52, no. 11, pp. 284-288, 2004.

[21] L. Ma, K. M. Li, S. S. Xiao et al., "Research on effects of blast casting vibration and vibration absorption of presplitting blasting in open cast mine," Shock and Vibration, vol. 2016, Article ID 4091732, 9 pages, 2016.

[22] Y. Gao, Y. Tian, S. Yang et al., "Experimental study on throwing law of blasting with plane charges," Engineering Blasting, vol. 10, no. 2, pp. 13-16, 2004, in Chinese.

[23] L. Chi, Z. Zhang, A. Aalberg, and C. C. Li, "Experimental investigation of blast-induced fractures in rock cylinders," Rock Mechanics and Rock Engineering, vol. 52, no. 8, pp. 2569-2584, 2019.
[24] Y. Gao, D. Qian, M. Gong et al., "Research on optimal spacing of plane charge," Journal of University of Science and Technology Beijing, vol. 27, no. 2, pp. 129-131, 2005, in Chinese.

[25] W. Yuan, X. Su, W. Wang, L. Wen, and J. Chang, "Numerical study of the contributions of shock wave and detonation gas to crack generation in deep rock without free surfaces," Journal of Petroleum Science and Engineering, vol. 177, pp. 699-710, 2019.

[26] A. A. Czernikowski, Directional Casting Blast, China Architecture \& Building Press, Beijing, China, 1986.

[27] S. Wang and Y. Wei, "Fracture control in rock blasting," Journal of China University of Mining \& Technology, vol. 14, no. 3, pp. 113-120, 1985, in Chinese.

[28] S. Chen, M. Wang, Y. Zhao et al., "Time-stress history on interface between cracked and uncracked zones under rock blasting," Chinese Journal of Rock Mechanics and Engineering, vol. 22, no. 11, pp. 1784-1788, 2003, in Chinese.

[29] Q. Zong and D. Meng, "Influence of different kinds of hole charging structure on explosion energy transmission," Chinese Journal of Rock Mechanics and Engineering, vol. 22, no. 4, pp. 641-645, 2003, in Chinese.

[30] X. F. Deng, J. B. Zhu, S. G. Chen, Z. Y. Zhao, Y. X. Zhou, and J. Zhao, "Numerical study on tunnel damage subject to blastinduced shock wave in jointed rock masses," Tunnelling and Underground Space Technology, vol. 43, no. 6, pp. 88-100, 2014.

[31] Y. Hu, N. Li, X. Han et al., "Calculating method of blasting load in rock slope engineering," Journal of Water Resources and Architectural Engineering, vol. 3, no. 1, pp. 49-52, 2005, in Chinese.

[32] L. Wu, W. Lu, and Q. Zong, "Distribution of explosive energy consumed by column charge in rock," Rock and Soil Mechanics, vol. 27, no. 5, pp. 735-739, 2006.

[33] H. L. Fei and C. C. Hong, "Study on crushed and fracture zone range under combined action of stress and detonation gas," Blasting, vol. 34, no. 1, pp. 33-36, 2017, in Chinese.

[34] M. Lanari and A. Fakhimi, "Numerical study of contributions of shock wave and gas penetration toward induced rock damage during blasting," Computational Particle Mechanics, vol. 2, no. 2, pp. 197-208, 2015.

[35] X. Zhao, D. Liu, G. Cheng et al., "Analysis of blasting gas mechanism and rock crack growth," Journal of Chongqing University, vol. 34, no. 6, pp. 75-80, 2011, in Chinese.

[36] C. H. Dowding, Blast Vibration Monitoring and Control, Prentice-Hall, Upper Saddle River, NJ, USA, 1985.

[37] W. B. Lu and Z. Y. Tao, "A study of fracture propagation velocity driven by gases of explosion products," Explosion and Shock Waves, vol. 14, no. 3, pp. 264-268, 1994.

[38] A. Fakhimi and M. Lanari, "DEM-SPH simulation of rock blasting," Computers and Geotechnics, vol. 55, pp. 158-164, 2014.

[39] L. Ma, K. Li, X. Ding et al., "Study on the influencing factors on casting distance of rock by casting blast," Engineering Blasting, vol. 19, no. 1-2, pp. 50-53, 2013, in Chinese.

[40] L. Ran and J. Li, "The application of factor analysis in the evaluation of comprehensive performance of listed companies on the small and medium-sized enterprises board," Application of Statistics and Management, vol. 24, no. 1, pp. 75-80, 2005, in Chinese.

[41] S. S. Xiao, H. S. Wang, and G. W. Dong, "A preliminary study on the design method for large-diameter deep-hole presplit blasting and its vibration-isolation effect," Shock and Vibration, vol. 2019, Article ID 2038578, 11 pages, 2019.

[42] Q. Zong, "Theoretical analysis of mechanism of rock fragmentation in column charge blasting," Mining and Metallurgical Engineering, vol. 24, no. 8, pp. 1-3, 2004. 